\title{
EDITORIAL
}

\section{Treatment of Hepatitis C Virus Infection}

The hepatitis $\mathrm{C}$ virus (HCV) can cause both acute and chronic hepatitis. The acute process rarely causes hepatic failure, but usually leads to chronic infection. In contrast, chronic $\mathrm{HCV}$ infection clearly linked to advanced liver disease, hepatocellular carcinoma (HCC), and has become the leading indication for liver transplantation. Treatment of chronic $\mathrm{HCV}$ is aimed at slowing disease progression, preventing complications of cirrhosis, reducing the risk of HCC, and treating extrahepatic complications of the virus. The natural history of hepatitis $\mathrm{C}$ is quite variable. Up to $85 \%$ of patients with acute $\mathrm{HCV}$ eventually progress to chronic infection. Of them, $15-20 \%$ of patients will develop cirrhosis within 15-20 years. ${ }^{1}$

Candidacy for therapy of hepatitis $\mathrm{C}$ includes persons who are 18 years of age or older, are willing to be treated, and do not have contraindications to treatment if they have detectable HCV RNA in serum and evidence of chronic hepatitis suggested by elevated serum alanine aminotransferase levels or the presence of considerable necroinflammatory activity and fibrosis on liver biopsy. At present, the recommended therapy for chronic hepatitis $\mathrm{C}$ is a combination of formulations of interferon alfa and ribavirin (RBV). ${ }^{2}$ Interferon alfa is a cytokine that has an important function in the innate antiviral immune response. ${ }^{3}$ It acts by attaching to cell-surface receptors that signal through the system of Janus-activated kinase and signal transducers and activators of transcription, leading to induction of multiple interferon-stimulated genes. ${ }^{4}$ These genes include double-stranded RNases, inhibitors of viral protein translation, and proteins that destabilize viral messenger RNA. Interferon alfa also induces the expression of genes involved in the immune response, resulting in activation of natural killer cells, maturation of dendritic cells, proliferation of memory $\mathrm{T}$ cells, and prevention of T-cell apoptosis. ${ }^{5}$ Ribavirin is an oral nucleoside analogue with broad activity against viral pathogens. ${ }^{3}$ Its mechanism of action against $\mathrm{HCV}$ is not completely clear. Ribavirin appears to have minimal direct activity against $\mathrm{HCV}$ replication, ${ }^{6}$ but it may lead to rapid and lethal mutation of virions or depletion of intracellular guanosine triphosphate, which is necessary for viral RNA synthesis. ${ }^{7,8}$ Ribavirin also has immuno modulatory effects.
Definitions ${ }^{9}$ of response to treatment are: rapid virological response (RVR) is defined as nondetectability of serum HCV RNA $(<50 \mathrm{IU} / \mathrm{mL})$ after 4 weeks of therapy, early virological response (EVR) is defined as undetectable HCV RNA $(<50 \mathrm{IU} / \mathrm{mL})$ or at least a $2 \log$ decrease in serum HCV RNA from baseline level after 12 weeks of therapy, end-oftreatment virological response (ETVR) is indicated by non-detectability of HCV RNA at the end of therapy, sustained virological response (SVR) is defined as undetectable serum HCV RNA $(<50$ $\mathrm{IU} / \mathrm{mL}$ ) 24 weeks after the end of therapy. SVR has been shown to have the following beneficial effects: (i) fibrotic regression; (ii) substantially reduced rate of HCC; (iii) decreased rate of other complications, including liver failure and liver-related death; and (iv) improved quality of life. The most recent important advance in the treatment of hepatitis $\mathrm{C}$ was the development of a long-acting interferon, pegylated interferon (peginterferon), produced by the covalent attachment of polyethylene glycol to the interferon molecule. With its increased half-life, peginterferon can be given as a weekly dose. ${ }^{10}$ Two peginterferon formulations are currently approved for the treatment of hepatitis C: alfa-2a (Pegasys, Roche) and alfa-2b (Peg-Intron, Schering-Plough). In two large trials of these agents, the rates of sustained virologic response to a 48 -week course of peginterferon and ribavirin were 54 and $56 \%$, as compared with 44 and $47 \%$ with standard interferon and ribavirin and only $29 \%$ with peginterferon alone. ${ }^{11,12}$ Response rates were higher among patients with genotype 2 or 3 than among those with genotype 1 . A subsequent trial of different regimens of peginterferon alfa- $2 \mathrm{a}$ and ribavirin showed that patients with genotype 2 or 3 could be treated with a lower dose of ribavirin $(800 \mathrm{mg}$ rather than 1000 to $1200 \mathrm{mg}$ daily) and that the rates of sustained virologic response after 24 weeks of therapy ( 81 and $84 \%$ ) were similar to the rates after 48 weeks of therapy (79 and $80 \%) .{ }^{13}$ The following have been shown to influence treatment outcome: (i) age; (ii) sex; (iii) virus genotype; (iv) virus load; and (v) stage of fibrosis, especially F3, F4.

There are few absolute contraindications for use of peg-IFN-a and ribavirin. They include- present or 
past psychosis or severe depression, uncontrolled seizures, hepatic decompensation, pregnancy (RBV), renal failure (RBV), severe heart disease (RBV). The relative contraindications for IFN and ribavirin are history of depression, uncontrolled diabetes mellitus, uncontrolled hypertension, retinopathy, psoriasis, autoimmune thyroiditis or other active autoimmune disorders including autoimmune hepatitis, symptomatic heart disease or severe vascular disease (RBV), anemia/ischemic vascular disease (RBV). In addition to these contraindications special caution is required if IFN is administered in the circumstances like neutropenia (neutrophil count $<1,500$ cells $/ \mathrm{cmm}$ ), thrombocytopenia (platelet count $<85,000 / \mathrm{cmm}$ ), organ transplantation, history of autoimmune disease, presence of thyroid autoantibodies, age older than 65 years. Side-effects related to IFN include: cytopenia, abnormalities of thyroid function, depression, irritability, concentration and memory disturbances, visual disturbances, fatigue, muscle aches, headaches, nausea and vomiting, loss of appetite and weight, low grade fever and skin irritation, insomnia, hearing loss, tinnitus, interstitial fibrosis and hair thinning. Sideeffects associated with ribavirin include hemolytic anemia, fatigue, itching, rash, cough, gastrointestinal upset, pharyngitis, gout and birth defects. Serious side effects of combination therapy occur in 1 to $2 \%$ of patients, and permanent injury and death can occur. ${ }^{14}$ There are several areas of uncertainty in the treatment of hepatitis $\mathrm{C}$ like use in children, patients $>65$ years and/or with significant comorbidities, body mass index $>30$ and hepatic steatosis, persistently normal serum ALT, acute hepatitis C, patients with minimal histologic evidence of liver disease, genotype 4-6 infections, decompensated cirrhosis, failed to respond or have relapsed with prior $\mathrm{HCV}$ therapy, substance abuse disorders including alcoholics, HIV/HCV coinfection, renal disease including haemodialysis, history of solid organ transplantation.

Efforts have been made to develop new molecules for better treatment outcomes. Potential targets and approaches in the next 5 years are on long acting IFN, direct antiviral agents like polymerase and protease inhibitors, ribavirin analogues, immunomodulators and therapeutic vaccines. Peginterferon alpha and ribavirin represents the best current treatment available. Major limitations are cost and sensible side-effects. However SVR rates are promising that can even ensure hepatitis $\mathrm{C}$ a curable disease.

Professor Mobin Khan, Chairman, Department of Hepatology, Bangabandhu Sheikh Mujib Medical University, Dhaka, E-mail: mobin@bdonline.com

Dr. Md. Golam Azam, MBBS, MD, Hepatologist and Senior Researcher, BIRDEM Hospital, Dhaka, Email: birdem azam@yahoo.com

(J Bangladesh Coll Phys Surg 2008; 26: 1-2)

\section{References:}

1 Poynard T, Bedossa P, Opolon P. Natural history of liver fibrosis progression in patients with chronic hepatitis $\mathrm{C}$. Lancet 1997; 349: 825-32.

2 National Institutes of Health Consensus Development Conference Statement: management of hepatitis C: 2002 June 10-12, 2002. Hepatology 2002; 36: Suppl 1: S3-S20.

3 Feld JJ, Hoofnagle JH. Mechanism of action of interferon and ribavirin in treatment of hepatitis C. Nature 2005; 436: 967-72.

4 Sen GC. Viruses and interferons. Annu Rev Microbiol 2001; 55: $255-81$

5 Tilg H. New insights into the mechanisms of interferon á: an immunoregulatory and anti-inflammatory cytokine. Gastroenterology 1997; 112: 1017-21.

6 Lau JY, Tam RC, Liang TJ, Hong Z. Mechanism of action of ribavirin in the combination treatment of chronic $\mathrm{HCV}$ infection. Hepatology 2002; 35: 1002-9.

7 Maag D, Castro C, Hong Z, Cameron CE. Hepatitis C virus RNA-dependent RNA polymerase (NS5B) as a mediator of the antiviral activity of ribavirin. J Biol Chem 2001; 276: 46094-8.

8 Crotty S, Maag D, Arnold JJ, et al. The broad-spectrum antiviral ribonucleoside ribavirin is an RNA virus mutagen. Nat Med 2000; 6: 1375-9. [Erratum, Nat Med 2001; 7: 255.]

9 APASL hepatitis $\mathrm{C}$ working party. Asian Pacific Association for the Study of the Liver consensus statements on the diagnosis, management and treatment of hepatitis $\mathrm{C}$ virus infection. J Gastroenterol Hepatol 2007; 22: 615-633.

10 Glue P, Fang JWS, Rouzier-Panis R, et al. Pegylated interferon-á2b: pharmacokinetics, pharmacodynamics, safety and preliminary efficacy data. Clin Pharmacol Ther 2000; 68: 556-67.

11 Manns MP, McHutchison JG, Gordon SC, et al. Peginterferon alfa- $2 b$ plus ribavirin compared with interferon alfa- $2 b$ plus ribavirin for initial treatment of chronic hepatitis $\mathrm{C}$ : a randomised trial. Lancet 2001; 358: 958-65.

12 Fried MW, Shiffman ML, Reddy KR, et al. Peginterferon alfa-2a plus ribavirin for chronic hepatitis $\mathrm{C}$ virus infection. N Engl J Med 2002; 347: 975-82.

13 Hadziyannis SJ, Sette H Jr, Morgan TR, et al. Peginterferon alfa-2a and ribavirin combination therapy in chronic hepatitis C: randomized study of treatment duration and ribavirin dose. Ann Intern Med 2004; 140: 346-55.

14 Hoofnagle JH and Seef LB. Peginterferon and Ribavirin for Chronic Hepatitis C. N Engl J Med 2006; 355: 2444-2451. 